Brit. J. industr. Med., 1956, 13, 270.

\title{
THE CYTOLOGICAL DIAGNOSIS OF BLADDER TUMOURS AMONGST DYESTUFF WORKERS
}

\author{
BY \\ J. G. S. CRABBE, W. C. CRESDEE, T. S. SCOTT, and M. H. C. WILliAMS \\ From I.C.I. Ltd., Industrial Hygiene Research Laboratories, Welwyn, and I.C.I. Ltd., Dyestuffs Division and \\ The Clayton Aniline Co. Ltd.
}

(RECEIVED FOR PUBLICATION ON APRIL 17, 1956)

\begin{abstract}
Tumours of the urinary bladder occurring amongst the general population usually disclose their presence by the onset of symptoms such as haematuria, dysuria, frequency, or pain. In some cases haematuria may develop from a small benign papilloma which offers a good chance of successful treatment, whilst in others the tumour may have reached large proportions and even metastasized before its discovery.
\end{abstract}

In 1920 Oppenheimer in Germany recommended regular microscopical examination of the urine for the presence of red blood cells as a means for the earlier detection of occupational bladder tumours. For similar reasons in 1934, Cresdee, Guest, and Wignall (unpublished) instituted such regular examinations in two British dyestuffs factories and shortly afterwards Hope and Scott (unpublished) applied them in a third factory. They hoped that red blood cells or other abnormal constituents in the urine might give an indication for cystoscopy before the onset of symptoms due to a tumour so that earlier diagnosis might afford a chance of more effective treatment. During the next 15 years Cresdee, Goldblatt, Scott, and Williams (unpublished) in Great Britain extended these examinations of wet unstained smears of urinary sediments to include more men at more frequent intervals. Many cases diagnosed by this means were included amongst those described by Goldblatt (1949) and by Scott (1952) and all of them were included in the figures used by Case, Hosker, McDonald, and Pearson (1954), and Case and Pearson (1954) in their survey of the incidence of the disease in Great Britain. They confirmed statistically that there was a significantly higher incidence of bladder tumours amongst men exposed to $a$ - and $\beta$-naphthylamine and benzidine than in the general population and revealed an occupational hazard of bladder tumours amongst men engaged in the manufacture of magenta and auramine.
Similar examinations of wet smears of urinary sediment have been used as an indication for cystoscopy in Germany for a number of years (Gross, 1940). In Switzerland, however, the urine was examined for occult blood in 1932 but by 1937, after consultation with American colleagues, routine cystoscopy was chosen as the most efficient method of achieving early diagnosis (Müller, 1951). Routine annual cystoscopy of exposed workers was first instituted in the United States of America in 1931 and has continued until recently with concurrent examinations of wet smears (Gehrmann, 1934; Gehrmann, Foulger, and Fleming, 1949). They even advocate the cystoscopy of all men before starting work. Similarly this procedure was adopted early in Italy and still continues to be applied (di Maio, 1937 and 1949). Many tumours have been diagnosed in this way, but there is no indication of what proportion of unaffected men have continued to undergo cystoscopy annually for up to 20 years. It is claimed by the above authors that regular annual cystoscopy can be achieved. In France Billiard-Duchesne (1949) published the results of his cystoscopies, but Aboulker, Gaultier, Benguigui, and Smagghe (1949) record the successful use of the wet smear technique which suggests that routine cystoscopy was not acceptable to them.

In Great Britain it is admitted that, although a substantial proportion of healthy men who have been at high risk might undergo cystoscopy on first demand, with repetition the numbers would quickly dwindle to levels which would invalidate any of its alleged advantages. Cystoscopy may be accompanied by some discomfort and is an operation which must be performed with great care if all sequelae are to be avoided. In Great Britain it has been the practice to restrict it to the necessary minimum. Furthermore, in practice, routine cystoscopy cannot be extended effectively to those persons with a relatively small exposure to carcinogens but 
who still have a remote chance of developing a bladder tumour. Some tumours may grow to inoperable proportions in a year, so that an annual cystoscopic examination does not afford complete cover, even if there were no defaulters and no complications.

For the reasons given above, routine cystoscopy was considered to be quite unsuitable for introduction into British factories. Since their inception in 1934, the examinations of wet unstained smears of urinary deposits have resulted in many presymptomatic diagnoses, but despite these successes, some cases were only discovered when inoperable.

The work of Papanicolaou and Marshall (1945) and of Papanicolaou (1947) suggested that a study of cells exfoliated from the bladder epithelium into the urine might offer another method of screening the population at risk. Accordingly in 1951 the Papanicolaou smear technique of urine examination was introduced into the three factories alongside the original wet, unstained smear technique. A preliminary report on the results of the first year of its application has been given by Crabbe (1952). These results were sufficiently encouraging to warrant the continuation and extension of the Papanicolaou technique during subsequent years and the subject of this paper is the evaluation of each of the two techniques against the symptoms and cystoscopic findings.

\section{Methods}

Collection of Samples.-At first, urine samples were collected only from men working on suspect processes. When, however, some successes had been achieved, the wet smear examinations were extended to cover men who had left the hazardous processes and were employed on other work in the factory.

More recently, in two of the factories, the working histories of all persons employed have been examined and the employment cards of all persons who have at any time had the possibility of contact with known or suspected carcinogens are marked for the collection of urine samples. No difficulty has been experienced in obtaining samples and their regular collection is now regarded as one of the routines of factory life. A large proportion of men exposed to carcinogens in the past are now employed in a multitude of unrelated jobs elsewhere in the factories, and must be specially sought out to give their regular samples. The bottles are delivered to the men in the afternoon and collected full next morning.

In the third factory it has been possible to examine the urine of all the men. For geographical reasons it is convenient for them to attend at the surgery to void their samples. It is preferable to collect the urine in two jars and discard the first containing contamination from the urethra and prepuce, but this was only possible in the one factory where the men attend at the surgery, or when a special sample is demanded.
Wet Smear Technique.-About 10 to $15 \mathrm{ml}$. of fresh urine is centrifuged at approximately 2,000 r.p.m. for 15 minutes. A drop of the sediment is placed on a microscope slide. A cover slip can be applied, but this is not necessary for low- or medium-power examination and much time can be saved by dispensing with it.

The presence of red blood cells, leucocytes, and epithelial cells is noted, and a rough count of red cells is made. An experienced technician very quickly develops the ability to assess the number of cells present at a glance.

The decision to advise cystoscopy on wet smear examination alone always rests on the results of repeated examinations unless the urine contains sufficient blood to be visible to the naked eye, when cystoscopy becomes imperative. One of us (T. S. S.) examined the urine of 2,000 consecutive male applicants for employment, none of whom had previously been exposed to chemicals, and $124(6.2 \%)$ were rejected because of considerable numbers of red blood cells in the urine although there was no other factor which on physical examination would have been cause for rejection. Apart from this presence of red cells in the urine of a proportion of apparently healthy men, such cells may appear in the urine from other causes such as calculi, infection, or renal or prostatic disease; the problem is further intensified by the fact that certain aromatic amines, such as ortho-toluidine and 5-chlor-2-toluidine, can cause acute chemical cystitis with haematuria so that if a man with microscopic haematuria has a history of recent contact with such amines further urine examinations after his removal from exposure are necessary. Thus microscopic haematuria in a single sample cannot be taken as an absolute indication for cystoscopy.

The wet smear technique has diagnosed many tumours but is not specific. Where no tumour was detected other conditions of the urinary tract were occasionally found. Sometimes, however, a man with no detectable cause for the microscopic haematuria would undergo a negative cystoscopy on two or three occasions and then refuse at the very moment when cystoscopy was vital.

Although the presence of an abnormal number of red blood cells has been the usual criterion for cystoscopy, as pointed out by Nassauer (1920) the presence of pus cells in the urine of men previously exposed to carcinogens is also an indication for further investigation.

Each man's case has to be considered individually, taking into account the intensity and duration of exposure, the nature of the carcinogen and the time that has elapsed since first exposure, together with the severity and duration of the urinary abnormalities. For instance, inconclusive wet smears combined with a history of long and severe exposure would lead the medical officer to advise cystoscopy more readily than if the exposure had been moderate or negligible.

Papanicolaou Smear Technique.-About $40 \mathrm{ml}$. of urine is centrifuged at approximately 2,000 r.p.m. for 15 minutes and a portion of the sediment is smeared on to an albuminized slide. Without letting the smear dry, it is immediately placed in a fixative solution consisting of equal parts of $95 \%$ ethanol and ether for a minimum time of 10 minutes. It is then stained with haematoxylin, 
counterstained, and mounted. The preparations are permanent and can be kept indefinitely. A detailed description of this technique has been given by Papanicolaou and Marshall (1945).

Although it is preferable to use freshly voided urine when possible, this is not absolutely necessary. It has been stated by Sawaya, Sandin, and de Almeida (1954) that specimens of urine must be processed within one hour of micturition as the cells may be so altered as to render interpretation impossible. We have found that even in unfixed urine, cellular degeneration does not proceed so rapidly and the addition of absolute alcohol serves to fix and preserve the cells for as long as 96 hours at room temperature. It was, therefore, possible to collect the specimens at convenient points in two of the factories and to deliver them to the laboratories for processing later.

Sediments from the majority of both fresh and fixed normal urines contain so few cells that they appear to be almost acellular, and in order to reduce the time spent on the examination of the slides various methods have been devised to concentrate more cells into each smear. Chute and Williams (1948) and Ruth Graham (1950) advocate making smears from the pooled deposit of the whole urine samples. Deden (1954), on the other hand, allows $200-400 \mathrm{ml}$. of urine to stand for six hours in a separating funnel and then centrifuges the sediment, while Rofe (1955) removes the non-cellular elements by differential centrifugation and the mucus by solution in water after fixation of the cells. Though these methods are too prolonged for a busy laboratory where many urines per day are being processed, a modified form of differential centrifugation is being used successfully in one of our laboratories.

The interpretation of the smears is difficult and requires a thorough knowledge not only of the criteria of malignancy as laid down by Papanicolaou in his atlas (1954) but also of the numerous variations from the normal due to non-neoplastic conditions. While anyone can be trained in a matter of weeks to identify and record blood and epithelial cells in wet smears, it takes many months of instruction and practice before a technician can make a reliable assessment of the cytological characteristics of exfoliated cells. The results are interpreted as follows:-

$\left.\begin{array}{lll}\text { Class I } & \ldots \ldots \ldots \ldots \ldots & \text { Normal } \\ \text { Class II } \ldots \ldots \ldots \ldots & \text { Atypical }\end{array}\right\}$ Negative

Class III ................ Suspicious

$\left.\begin{array}{l}\text { Class IV } \ldots \ldots \text { Probably malignant } \\ \text { Class } V \text {..... Definitely malignant }\end{array}\right\}$ Positive
A positive result is considered an indication for cystoscopy. Suspicious smears are regarded as positive if exposure has been heavy or if blood is also present, but in other cases repeated samples are examined until a decision can be reached. The cases presented below will serve to illustrate the application of the Papanicolaou technique:-

Case 1.-This man was aged 51 when the tumour was found. He had been exposed to the manufacture of benzidine for seven years from 1933.

Routine wet smears of urine had been done from 1937 but had never suggested the presence of a tumour. Papanicolaou tests since 1951 were negative until May, 1955, when a suspicious result (Class III) was noted. Early in June the smear was Class II but on June 30 it became positive (Class IV). Cystoscopy on July 4 revealed a papilloma and this was confirmed as a benign tumour on biopsy.

Case 2.-This workman was aged 49 when the tumour was found. He had been exposed to benzidine for 20 years, from 1931.

His urine had been tested for R.B.C.s from 1943 onwards and showed no significant quantity of blood cells. Papanicolaou smears made on two separate occasions in December, 1953, were definitely positive. Because of this he was cystoscoped on January 25, 1954, and a small area of malignant tumour was revealed which was confirmed as transitional cell carcinoma by biopsy.

\section{Results}

During the five years 1951 to 1956 the urines of approximately 1,800 men were screened by the Papanicolaou smear technique and also, except for three cases, by the wet smear technique.

Of these 1,800 men, 91 were cystoscoped as a result of the two tests or on account of developing symptoms and 62 new cases of bladder tumour were discovered. The results are shown in Table I. (The examination of the urines of those men with a previous history of treated bladder tumour who have been under regular cystoscopic review is considered separately.)

Fifty-one men with positive Papanicolaou smears showed bladder tumours on first cystoscopy (true positives). (a) Twenty-six had symptoms and/or

TABLE 1

SMEAR RESULTS AND FINDINGS IN 91 MEN CYSTOSCOPED

\begin{tabular}{|c|c|c|c|c|c|c|c|c|}
\hline \multirow{2}{*}{\multicolumn{2}{|c|}{ Cystoscopic Findings }} & \multicolumn{7}{|c|}{ Smear Results and Findings in 91 Men Cystoscoped } \\
\hline & & $\begin{array}{c}\text { True } \\
\text { Positives }\end{array}$ & $\begin{array}{c}\text { Probably } \\
\text { True } \\
\text { Positives }\end{array}$ & $\begin{array}{c}\text { False } \\
\text { Negatives }\end{array}$ & Total & $\begin{array}{c}\text { False } \\
\text { Positives }\end{array}$ & $\begin{array}{c}\text { True } \\
\text { Negatives }\end{array}$ & Total \\
\hline $\begin{array}{l}\text { Symptoms and/or R.B.C.s } \\
\text { No symptoms }\end{array}$ & & 26 & $\begin{array}{l}4 \\
1\end{array}$ & $\begin{array}{l}6 \\
-\end{array}$ & $\begin{array}{l}36 \\
27^{*}\end{array}$ & $\begin{array}{l}4 \\
6\end{array}$ & $\begin{array}{r}18 \\
-\end{array}$ & $\begin{array}{r}22 \\
6\end{array}$ \\
\hline Total & $\ldots$ & 52 & 5 & 6 & $63^{*}$ & 10 & 18 & 28 \\
\hline
\end{tabular}


showed R.B.C.s on microscopy sufficient in themselves to be an indication for cystoscopy. (b) Twentyfive had not at any time had R.B.C.s or any other indication that a tumour was present. One man had positive Papanicolaou smears but no bladder tumour on cystoscopy, although a carcinoma of the prostate was discovered on clinical examination.

Five men with positive Papanicolaou smears, although showing no tumours on first cystoscopy, developed bladder tumours from five months to four years later (probably true positives). (a) Four had symptoms or R.B.C.s sufficient to warrant cystoscopy in any case. (b) One showed no R.B.C.s at any time.

Six men with negative Papanicolaou smears showed bladder tumours on first cystoscopy (false negatives). (a) Four were cystoscoped because of excessive R.B.C.s. (b) Two showed only occasional R.B.C.s and had symptoms .

Sixty-two cases of bladder tumour and one case of carcinoma of the prostate were detected.

Ten men had positive Papanicolaou smears, but no bladder tumours have so far been discovered on cystoscopy (false positives). (a) Three showed R.B.C.s sufficient in themselves to be an indication for cystoscopy. (b) One had slight symptoms. (c) Six showed only occasional R.B.C.s.

Eighteen men had negative Papanicolaou smears and no tumour on cystoscopy (true negatives). They were cystoscoped because (a) 11 showed R.B.C.s sufficient to be an indication for cystoscopy, and (b) seven had both R.B.C.s and symptoms.

Ninety-one men were cystoscoped.

\section{Discussion}

During the five years under review, 51 (76.1\%) out of 67 men with positive smears had bladder tumours on first cystoscopy and the figure becomes $57(85.1 \%)$ out of 67 when the five " probably true positives" and the carcinoma of prostate are included.

Men with negative Papanicolaou and wet smears were presumed to be clear of tumours in the absence of symptoms and were not submitted for cystoscopy. The fact that in the five years all the tumours found were at an early stage in their development on first examination suggests that this view is reasonable. In six cases it was found that a tumour was present when a Papanicolaou smear was negative but all of these had an excess of red blood cells or had symptoms.

Tables 2 and 3 show the results of the application of the wet smear technique and the Papanicolaou technique to the urine of the 91 men who were cystoscoped.

Tables 2 and 3 show that in applying the wet smear
TABLE 2

WET SMEAR RESULTS

\begin{tabular}{|c|c|c|c|}
\hline \multirow{2}{*}{ Cystoscopy } & \multicolumn{2}{|c|}{ Red Blood Cells or Symptoms } & \multirow{2}{*}{ Total } \\
\hline & Positive & Negative & \\
\hline $\begin{array}{l}\text { Tumour present } \\
\text { No tumour found }\end{array}$ & $\begin{array}{l}34 \\
20\end{array}$ & 25 & $\begin{array}{l}59 \\
29\end{array}$ \\
\hline Total & 54 & 34 & $88^{*}$ \\
\hline
\end{tabular}

* In three cases no wet smear tests were done.

TABLE 3

PAPANICOLAOU SMEAR RESULTS

\begin{tabular}{|c|c|c|c|}
\hline \multirow{2}{*}{ Cystoscopy } & \multicolumn{2}{|c|}{ Papanicolaou Test } & \multirow{2}{*}{ Tota } \\
\hline & Positive & Negative & \\
\hline $\begin{array}{l}\text { Tumour present } \\
\text { No tumour found }\end{array}$ & $\begin{array}{l}57^{*} \\
10\end{array}$ & $\begin{array}{r}6 \\
18\end{array}$ & $\begin{array}{l}63 \\
28\end{array}$ \\
\hline Total ... & 67 & 24 & 91 \\
\hline
\end{tabular}

technique to the urine of 88 of the men there were $25(28.4 \%)$ false negatives and $20(22.7 \%)$ false positive results whereas the Papanicolaou technique in 91 cases yielded only six $(6.6 \%)$ false negative and $10(11.0 \%)$ false positive results. From these data it can be concluded that the latter technique is superior as a diagnostic measure. In fact, as a result of the Papanicolaou technique 25 men were sent for investigation and a tumour detected before the onset of microscopic haematuria or any other indication that a tumour was present.

False Positive Results. -When cells with malignant characteristics are present in the urine and no growth is found anywhere in the urinary tract, the result is regarded as a false positive. At their first cystoscopy 15 men gave false positive results but five of them showed visible tumours on cystoscopic follow-up after five, 10, 11, 29, and 46 months respectively.

The following case is given as an example:-

Case 3.-This man was aged 58 when the tumour was found. He had been exposed to $\beta$-naphthylamine for eight years.

His urine was tested for R.B.C.s from 1936 onwards; occasional R.B.C.s had been apparent since 1950 but never of such significant number as to warrant cystoscopy. The Papanicolaou test showed malignant cells from March, 1953, onwards. He was investigated because of this in September, 1953, but no abnormality was seen except that on cystoscopy there was a little redness in a tiny area at the apex near the air bubble. Five weeks later, in October, 1953, the bladder looked more normal than previously and there was no change again in February, 1954. However, five months after this (July, 1954) and 10 months after the first cystoscopy a sessile tumour was found high up in the apex and a smaller tumour was seen near to the right ureteric orifice. 
Clinically they appeared to be papillomata, but biopsy revealed them to be carcinomata.

The finding of apparently malignant cells in the urine before a tumour actually becomes visible is comparable to the finding by von Haam and Menzies (1953) of malignant cells in vaginal smears from laboratory animals some time before the gross appearance of experimentally induced carcinoma of the cervix uteri.

Chute and Williams (loc. cit.) in their series of cases were surprised at the number of carcinomata of the prostate that gave rise to positive smears in the sediment from ordinary voided urine, as distinct from that passed following prostatic massage. Amongst our cases one man with positive Papanicolaou smears was found to have a carcinoma of the prostate.

However, amongst our 10 false positive cases there are four men who have repeatedly shown malignant cells in the smear during the past two years and a further three who have shown similar findings recently. In none of these cases so far has a tumour been found on cystoscopy. The following case is a typical example:-

Case 4.-A man aged 44 had had slight exposure to bladder carcinogens, but had occasional attacks of cystitis with pain and dysuria.

He has had a few red blood cells persistently in the urine since 1949. The first Papanicolaou smears in April, 1952, were strongly positive, and all subsequent smears have remained so. He was cystoscoped in September, 1952, and again in February, 1954, but no abnormality was found either in the bladder or elsewhere in the urinary tract.

Masina (1952) in this country and Melicow (1952) and Melicow and Hollowell (1952) in America have noted that normal-looking epithelium taken from tumour-bearing bladders removed at total cystectomy when examined microscopically showed foci of cellular activity which closely resembled areas of tumour formation and other areas which they thought might in time develop into obvious growths. These observations may help to explain the continuous false positive smears from men with apparently normal bladders. It remains to be seen whether these men will develop tumours of the renal pelvis, ureter, bladder, or prostate later.

The remaining three false positive cases had renal calculus, urethral stricture, and haematuria following extensive burns. Ferguson (1949) points out that there are certain non-neoplastic conditions which produce cells almost identical to malignant ones and give rise to misinterpretation.

False Negative Results. - When a growth is found in the urinary tract of a man whose urinary sediment never shows the presence of tumour cells, the result is a false negative. There were six false negative results in our series, of which the following case is an example.

Case 5.-This man was aged 52 when the tumour was found. He had been exposed to a-naphthylamine for 19 years from 1935. His urine had been tested for R.B.C.s from 1936, and by the Papanicolaou technique from 1951. Although occasional R.B.C.s were noted they never reached sufficient numbers to warrant cystoscopy and the Papanicolaou results were always negative until he developed acute haematuria in September, 1954. Cystoscopy revealed a benign papilloma which was confirmed by biopsy.

In five of these cases the growth was clinically of a simple papillary type. On section, four were histologically benign, whilst in the fifth the biopsy material was unsatisfactory. In the sixth case a solid type of carcinoma covered with slough and calcareous deposit was present.

"Benign" Papillomata.-Benign papillomata appear to vary very much in the cells which they shed, and in some cases as Dean (1948) and Leadbetter (1955) point out, the exfoliated cells show no recognizable difference from the normal. Papanicolaou (loc. cit.) says such growths may be recognized by the presence of cuboidal and columnar cells often arranged in groups and clusters, sometimes showing a palisade formation, and he puts them in the category of Class II, reporting them as atypical but suggestive of benign papilloma. However, he says, "their occasional presence in cases in which there is no evidence of such a growth limits their diagnostic significance", and also that " intermediate cell types from the prostate are also seen, some with a cuboidal or columnar form reminding one of cells exfoliated from a benign papillary growth ". McDonald (1954) says that it is exceedingly difficult to distinguish benign papillomata unless fronds of tissue are exfoliated, while Osborn (1953) observes that such fragments of tissue show little cellular variation. Other authors (Chute and Williams loc. cit.; Schmidlapp and Marshall, 1950; Deden, loc. cit.) have come to the conclusion that cells from benign papillomata do not usually deviate from the normal sufficiently to permit a diagnosis and that amongst their cases their false negative results were mostly such tumours.

Our experience of these benign tumours is of considerable interest. Fifty-six men had bladder tumours in association with the exfoliation of abnormal cells. In 53 of them these cells had apparently malignant characteristics and in the other three only clumps of " benign papilloma" 
cells were seen. Yet, of these 56 men, 29 had clinically benign papillomata; 15 of these were confirmed by biopsy, four proved to be malignant on biopsy, and 10 were treated without biopsy. Twenty-seven men had clinical carcinomata; 22 were confirmed by biopsy.

Thus, 26 out of 29 men with clinically benign papillomata had apparently malignant cells in the urine, yet only four out of 19 of these tumours were found to be malignant on biopsy. Although it is tempting to suggest that malignant changes were already taking place in these tumours, such an assumption would lead to an abnormally high incidence of malignancy amongst them. No satisfactory explanation is available to explain the finding of cells with apparently malignant characteristics in the urine from such a high proportion of bladders containing benign tumours. In our experience it has not been possible to predict the precise nature of the tumours from the appearance of the exfoliated cells. Nevertheless, these results show that, contrary to many opinions, the Papanicolaou technique is capable of detecting a significant proportion of benign papillomata.

Use of Papanicolaou Technique in Follow-up of Treated Cases.-As there is a continuing liability for further tumours to appear in persons who have been treated for a bladder tumour, it is essential that cystoscopic reviews should be continued for life. It was hoped, when the Papanicolaou technique was introduced, that it could be substituted for at least some of these review cystoscopies. We have applied this test to a group of $\mathbf{4 2}$ men who have had tumours treated (Table 4).

TABLE 4

RESULTS OF 225 REVIEW CYSTOSCOPIES OF 42 MEN COMPARED WITH RESULTS OF SMEARS BEFORE EACH CYSTOSCOPY

\begin{tabular}{l|c|c|c|c}
\hline $\begin{array}{c}\text { Papanicolaou } \\
\text { Smear } \\
\text { Results }\end{array}$ & \multicolumn{3}{|c|}{ Cystoscopy } & Total \\
\cline { 2 - 4 } & Negative & Suspicious & Positive & \\
\hline Negative & 83 & 10 & 20 & 113 \\
Suspicious & 19 & 20 & 4 & 43 \\
Positive & 27 & 27 & 15 & 69 \\
\hline Total & 129 & 57 & 39 & 225 \\
\hline
\end{tabular}

From this it appears that dependence cannot be placed on the result of Papanicolaou smears from men with a previous history of a treated tumour. Some individuals showed complete agreement all the time, while others continually showed false positive or false negative results. At the present stage of our investigation it can therefore only be said that the stained smear technique is unreliable in reviewing established cases. It is too early yet to know whether these false positive smears have any prognostic significance.

\section{Conclusions}

Our experience over the past five years has shown that the Papanicolaou technique can be successfully used as a method of screening the urine of an industrial population. This confirms the suggestions of Case (unpublished, 1949) and of Cromwell and Papanicolaou (1952) that cytological examination of the urine would be of value in detecting industrial bladder tumours. The most important advantage of the method is its ability to indicate the presence of a tumour at a very early stage of its development, often before any presenting symptoms or other urinary abnormalities have given an indication of its presence. Poole-Wilson (1953) observes that on account of routine medical examination in industry occupational bladder tumours tend to be seen in an earlier stage than those arising spontaneously.

To obtain the best results both the Papanicolaou and the wet smear technique should be employed together. On the other hand, wet smears of concentrated deposit can be examined for epithelial cells, and a Papanicolaou smear only made and examined if such cells are seen. If the urine is acellular much time and trouble can be saved in this way without a significant loss of efficiency. By this means it is possible to maintain a much more comprehensive and frequent check on large industrial populations than can be achieved by the use of routine cystoscopy. It is also possible to include considerable groups of workers whose chance of tumour development may only be remote.

Routine annual cystoscopy of persons with high risk is claimed to be practicable abroad. If it had been used as a screening method on this population it would have involved at least 8,000 cystoscopies. in five years compared with the 91 carried out for us. The fact that early diagnosis was achieved in our cases leads us to believe that the techniques we have described offer very considerable advantages. We consider that they are indispensable, if all necessary care is to be given to workers in any factory where a hazard of industrial bladder tumours exists.

\section{Summary}

A description is given of cytological methods of achieving early diagnosis of occupational bladder tumours. The results obtained by examining the urine of some 1,800 workers for the presence of microscopic haematuria and by the Papanicolaou technique are reported together with the cystoscopic findings amongst 91 men.

The advantages and disadvantages of the two techniques are discussed.

It is concluded that the Papanicolaou technique offers considerable advantages in the diagnosis of benign and malignant tumours of the bladder, and 
that this, coupled with the examination of urine for red blood cells, is the method of choice for screening an industrial population with a high risk of such tumours.

We should like to thank Dr. Alexander Munn for his assistance in this work, and Miss M. Grice, Miss D. Jackson, Miss L. North (Imperial Chemical Industries, Dyestuffs Division), and Mr. E. Booth (The Clayton Aniline Company Ltd.) for processing and examining the slides by both techniques.

We are indebted to Mr. M. L. Kennedy, Huddersfield Royal Infirmary, and Mr. D. S. Poole-Wilson, Salford Royal Hospital and Christie Hospital and Holt Radium Institute, Manchester, the urologists under whose care the majority of our patients were treated. Mr. PooleWilson gave us much valuable advice in the preparation of this paper.

\section{REFERENCES}

Aboulker, P., Gaultier, M., Benguigui, M., and Smagghe, G. (1949). Arch. Mal. prof., 10, 370.

Billiard-Duchesne, J. F. (1949). Proc. Ninth int. Congr. industr. Med., London, 1948, p. 507. Wright, Bristol.

Case, R. A. M., Hosker, M.E., McDonald, D. B., and Pearson, J. T. (1954). British Journal of Industrial Medicine, 11, 75.

Chute, R., and Williams, D. W. (1948). J. Urol., 59, 604.

Crabbe, J. G. S. (1952). Brit. med. J., 2, 1072

Cresdee, W. C., Guest, D., and Wignall, T. H. (1934). Unpublished.
Cromwell, H. A., and Papanicolaou, G. N. (1952). Arch. industr. Dean, Ayg., 5, 232.

Dean, A. L. (1948). J. Urol. (Baltimore), 59, 614

Deden, C. (1954). Acta radiol. (Stockh.), Suppl. 115, 18.

Ferguson, J. H. (1949). Cancer, 2, 845.

Gehrmann, G. H. (1934). J. Urol. (Baltimore), 31, 126 $\longrightarrow$, Foulger, J. H., and Fleming, A. J. (1949), Proc. Ninth int.

Goldblatt, M. W. (1949). British Journal of Industrial Medicine, 6,65 .

Graham, R. M. (1950). The Cytologic Diagnosis of Cancer (Vincent Memorial Hospital), p. 208, Saunders, Philadelphia.

Gross, E. (1940). Angew. Chem., 53, 368.

Haam, E. von, and Menzies, P. (1953). Proc. Amer. Ass. Cancer Res., 1, 22.

Hope, J., and Scott, T. S. (1936). Unpublished.

Leadbetter, W. F. (1955). "CA.", Bull. of Cancer Prog., 5, 131

McDonald, J. R. (1954). Amer. J. clin. Path., 24, 684.

Maio, G. di (1937). Arch. ital. Urol., 14, 283. 1949). Proc. Ninth int. Congr. industr. Med., London,

Masina, F. (1952). Brit. J. Urol., 24, 344.

Melicow, M. M. (1952). J. Urol. (Baltimore), 68, 261.

Melicow, and Hollowell, J. W. (1952). Ibid., 68, 763

Müller, A. (1951). Helv. chir. Acta, 18, 1.

Mäller, A. (1951). Helv. chir. Acta, 18, 1.

Nassauer, M. (1920). Frankfurt Z. Path., 22, 35

Oppenheimer, R. (1920). Zbl. Gewhyg., 8, 105. Osborn, G. R. (1953). Applied Cytology, p. 146. But
Papanicolaou, G. N. (1947). J. Urol., 57, 375.

Papanicolaou, G. N. (1947). J. Urol., 57, 375. (1954). Atlas of Exfoliative Cytology, pp. 13, 38, and 39.
(Commonwealth Fund), Harvard University Press, Cambridge. Mass.

, and Marshall, V. F. (1945). Science, 101, 519.

Poole-Wilson, D. S. (1953). In Modern Trends in Urology, p. 401, ed. E. W. Riches. Butterworth, London.

Rofe, P. (1955). J. clin. Path., 8, 25.

Sawaya, M., Sandin, D., and Almeida, L. C. de (1954). J. Amer. med. Ass., 154, 931 .

Schmidlapp, C. J., and Marshall, V. F. (1950). N.Y. St. J. Med., 50,56

Scott, T. S. (1952). British Journal of Industrial Medicine, 9, 127. 